\title{
Patterns of death among avalanche fatalities: a 21-year review
}

\author{
Jeff Boyd MBBS, Pascal Haegeli PhD, Riyad B. Abu-Laban MD MHSc, Michael Shuster MD, \\ John C. Butt MD CM
}

Published at www.cmaj.ca on Feb. 12, 2009.

$\infty \infty$

See related commentary by Brugger, page 491

\section{ABSTRACT}

Background: Avalanches are a significant cause of winter recreational fatalities in mountain regions. The purpose of this study was to determine the relative contributions of trauma and asphyxia to avalanche deaths.

Methods: We reviewed all avalanche fatalities between 1984 and 2005 that had been investigated by the offices of the British Columbia Coroners Service and the Chief Medical Examiner of Alberta. In addition, we searched the database of the Canadian Avalanche Centre for fatal avalanche details. We calculated injury severity scores for all victims who underwent autopsy.

Results: There were 204 avalanche fatalities with mortality information over the 21-year study period. Of these, 117 victims underwent autopsy, and 87 underwent forensic external examination. Asphyxia caused 154 (75\%) deaths. Trauma caused $48(24 \%)$ deaths, with the rate of death from trauma ranging from $9 \%(4 / 44)$ for snowmobilers to $42 \%(5 / 12)$ for ice climbers. In addition, $13 \%$ (12/92) of the asphyxia victims who underwent autopsy had major trauma, defined as an injury severity score of greater than 15 . Only $48 \%$ (23/48) of victims for whom trauma was the primary cause of death had been completely buried.

Interpretation: Asphyxia and severe trauma caused most avalanche fatalities in western Canada. The relative rates differed between snowmobilers and those engaged in other mountain activities. Our findings should guide recommendations for safety devices, safety measures and resuscitation.

Une version française de ce résumé est disponible à l'adresse www.cmaj.ca/cgi/content/full/180/5/507/DC1

CMAJ 2009;180(5):507-12

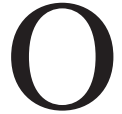
ver the past 30 years (1978-2007), avalanches have been responsible for 329 deaths in Canada, with a recent rate of 14 deaths per year. ${ }^{1}$ Avalanches kill a disproportionate number of young people, with victims most commonly being in their 20s. ${ }^{2-5}$ Outdoor recreation accounts for $92 \%$ of avalanche deaths in Canada, and $88 \%$ of deaths occur in the provinces of British Columbia and Alberta.
Mountain rescue agencies emphasize avalanche avoidance strategies but also make recommendations for safety devices and resuscitation techniques. ${ }^{6,7}$ One such safety device, an airbag designed to increase flotation and prevent burial, reduced the mortality rate in a European study. ${ }^{8}$ However, the results of that study may not be generalizable to Canada, as it used Swiss and Austrian data, which reflect the European preponderance of avalanche deaths from asphyxia and a reported rate of trauma death of $5.6 \% .^{9}$ In contrast, a National Research Council study of human and property loss in Canada reported that trauma was the cause of death in $27 \%$ of avalanche deaths in this country. ${ }^{10}$ Snowmobilers have become the fastest growing and probably the largest activity group exposed to avalanches in North America, ${ }^{11-13}$ yet this activity is not common in Europe. Similarly, so-called helicat skiers, who use helicopters or snowcats (vehicles with an enclosed cab and tracks for travelling on snow) to reach their starting point, are not represented in European statistics.

Our purpose was to determine the relative contributions of trauma and asphyxia to avalanche deaths in western Canada and to determine whether this varies between different activity groups.

\section{Methods}

\section{Study population}

In this retrospective observational case series, we investigated all snow avalanche deaths in British Columbia and Alberta between Apr. 1, 1984, and Apr. 5, 2005. This date range coincided with entries of avalanche data in the Canadian Avalanche Centre Avalanche Incident Database that were complete upon study inception. We included all victims who died from snow avalanches, as the primary event, in outdoor terrain. 
The research protocol for this study was approved by the research ethics review committee of the College of Physicians and Surgeons of Alberta.

\section{Data collection and abstraction}

We identified records for avalanche deaths in the Canadian Avalanche Centre database, which is compiled from input fields on a standardized avalanche report form..$^{14}$ One of the investigators (P.H.), who was blinded to cause of death and other findings as recorded in autopsy and external examination reports, extracted avalanche data from this database.

We also identified avalanche fatalities by searching the databases of the Chief Coroner of British Columbia and the Chief Medical Examiner of Alberta using the term "avalanche" as the underlying cause or otherwise related to the cause of death. A second study investigator (J.B.) extracted mortality data from these files using explicit criteria and a standardized format. He was blinded to the avalanche data associated with each record. Data extracted included all causeof-death fields, results of investigations conducted at the scene, findings of autopsy and external examination, and results of toxicology testing. Staff of the British Columbia Coro-

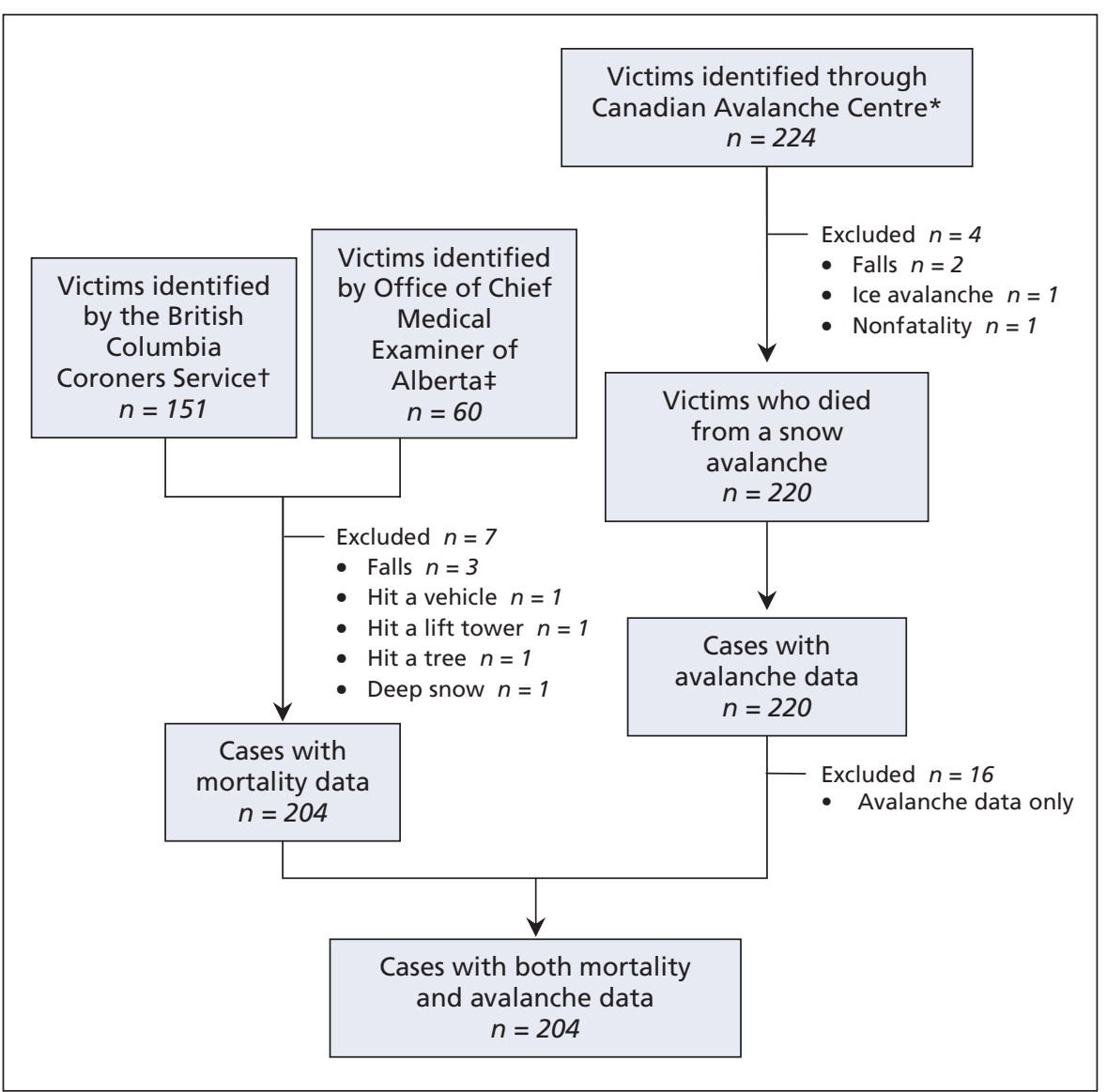

Figure 1: Case flow in a study of avalanche-related fatalities in British Columbia and Alberta, 1994-2005. *All victims reported to the Canadian Avalanche Centre as having died from avalanches in British Columbia and Alberta. †All avalanche fatalities investigated by the Office of the Chief Coroner of British Columbia. $¥ A$ All avalanche fatalities investigated by the Office of the Chief Medical Examiner of Alberta. ners Service and the Office of the Chief Medical Examiner of Alberta then searched their respective databases for specific victims who were reported in the database of the Canadian Avalanche Centre but had not been found using the term "avalanche" in the initial searches. Files for each case were reconciled using the date and location of the incident and the name and date of birth of the person who died and were merged into a single database for analysis.

For all cases in which an autopsy was conducted, we quantified trauma severity by calculating injury severity scores. ${ }^{15,16}$ The injury severity score is an index of anatomic injury severity ranging from 1 to 75 , with higher scores indicating more severe injury and scores over 15 defined as major trauma. ${ }^{16}$ This score is based on the Abbreviated Injury Scale, ${ }^{17}$ which scores each specific injury on an ordinal scale from 1 (minor injury) to 6 (maximal and currently untreatable). The injury severity score is calculated by dividing the body into 6 regions, identifying the 3 regions with the highest scores and summing the squared values of these 3 scores. ${ }^{15,16}$ The injury severity score was calculated by use of information from full autopsy reports and not reports limited to external examination.

The sole abstractor (J.B.) for mortality data received training in calculating injury severity scores from a full-time trauma data analyst. Before scoring the study autopsies, we assessed the reliability of the calculations by comparing scoring and calculation performance between the sole abstractor and the trauma data analyst. This was done using a random selection of 8 cases, each requiring assessments in 6 injury regions (48 scores total). The 2 abstractors were blinded to each other's results. Reliability, as determined by weighted kappa scores, ${ }^{18}$ was excellent (weighted kappa score $0.89,95 \%$ confidence interval [CI] 0.81-0.97).

\section{Statistical analysis}

We developed the questions for our primary analysis and corresponding outcome measures by consensus before undertaking any aspect of the analysis. We limited our analysis to cases for which we obtained both mortality and avalanche data.

We first generated standard descriptive statistics. We then performed comparative analyses of the cause of death by examination technique (autopsy v. external exam), the cause of death by activity group and the degree of burial by cause of death using 2 -tailed $\chi^{2}$ tests. We compared burial time and depth by cause of death using the Wilcoxon ranksum test with continuity correction. We derived confidence intervals for proportions from exact binomial calculations. ${ }^{19}$ 


\section{Results}

We identified 224 potentially eligible avalanche deaths in the Canadian Avalanche Centre database and a total of 211 potentially eligible deaths in the 2 provincial coroner databases. We excluded asphyxia deaths from nonavalanche causes; deaths caused by hitting an object in the absence of an avalanche, by mountaineering falls and by ice avalanches; and deaths in liftserviced ski areas, buildings and vehicles. After these exclusions, mortality data with corresponding avalanche data were available for 204 cases (Figure 1). In 117 cases (57\%), an autopsy had been performed. In the remaining 87 cases, a forensic external examination without dissection had been conducted.

The immediate cause of death was asphyxia in 154 cases

Table 1: Cause of death as determined by autopsy or external examination for 204 avalanche fatalities in western Canada

\begin{tabular}{lrrrrrr}
\hline & \multicolumn{6}{c}{ No. (\%) of deaths } \\
\cline { 2 - 7 } $\begin{array}{l}\text { Immediate cause } \\
\text { of death }\end{array}$ & Autopsy & $\begin{array}{c}\text { External } \\
\text { examination* }\end{array}$ & All deaths* \\
\hline Asphyxia & 92 & $(79)$ & 62 & $(71)$ & 154 & $(75)$ \\
\hline Trauma & 25 & $(21)$ & 23 & $(26)$ & 48 & $(24)$ \\
\hline Hypothermia & 0 & $(0)$ & 2 & $(2)$ & 2 & $(1)$ \\
\hline Total & 117 & $(100)$ & 87 & $(100)$ & 204 & $(100)$ \\
\hline
\end{tabular}

*No significant difference in the distribution of causes of death between autopsy and external examination (2-tailed Pearson $\chi^{2}$ test, $\left.p=0.17\right)$.
( $75 \%)$, trauma in 48 cases $(24 \%)$ and hypothermia in 2 cases (1\%) (Table 1).

Snowmobilers represented $44(22 \%)$ of the fatalities, whereas helicat skiers represented 43 (21\%) (Table 2). Definitions of all activities are provided in Table 2.

Overall, $179(88 \%)$ of the victims were male (Table 2, Appendix 1, available at www.cmaj.ca/cgi/content/full/180 /5/507/DC2). The median age of the study population was 33 (interquartile range 26-43) years, and the largest single age group was 20-29 years (59/203 or 29\%). Helicat skiers were generally older (median 43 years, interquartile range 30-48 years) and out-of-bounds skiers younger (median 20 years, interquartile range 17-30 years) (Table 2 ).

Trauma was the cause of death for $4(9 \%$; $95 \%$ CI $3 \%-$ $22 \%$ ) of the 44 snowmobilers, similar to the overall trauma death rate reported in European avalanche statistics. ${ }^{9}$ In contrast, 13 (30\%; 95\% CI 17\%-46\%) of the 43 deaths involving helicat skiers were caused by trauma, a proportion that differs substantially from European data.

The median injury severity score in trauma deaths was 30 (interquartile range 22-75) (Table 3). In asphyxia deaths, the injury severity score exceeded 15 in 12 (13\%) of the 92 cases with an autopsy.

Chest trauma was the most common injury, representing $46 \%(11 / 24)$ of cases with single-system trauma. In these cases, the median Abbreviated Injury Scale score for the thoracic region was 4 (interquartile range 3.5-4), which is ranked as severe in the Abbreviated Injury Scale dictionary. ${ }^{17}$ Head injury represented $42 \%(10 / 24)$ of the cases with

Table 2: Characteristics of victims and distribution by activity group of asphyxia and trauma deaths

\begin{tabular}{|c|c|c|c|c|c|c|c|c|c|c|c|}
\hline \multirow{2}{*}{$\begin{array}{l}\text { Activity } \\
\text { Backcountry skiingף }\end{array}$} & $\begin{array}{l}\text { No. }(\%) \\
n=204\end{array}$ & $\begin{array}{l}\text { Age, median } \\
\text { (IQR), yr } \\
n=203^{*}\end{array}$ & \multicolumn{2}{|c|}{$\begin{array}{c}\text { Sex, no. }(\%) \\
\text { male } \\
n=204\end{array}$} & \multicolumn{2}{|c|}{$\begin{array}{c}\text { Resident of } \\
\text { Canada, no. }(\%) \\
n=188\end{array}$} & \multicolumn{5}{|c|}{ Immediate cause of death $(n=202) \dagger$} \\
\hline & $62(30)$ & $32(26-42)$ & $49 / 62$ & (79) & $46 / 60$ & (77) & $46 / 62$ & (74) & $16 / 62$ & (26) & $\frac{95 \% \mathrm{CI}}{16-38}$ \\
\hline Snowmobiling & $44(22)$ & $36(28-42)$ & $42 / 44$ & (95) & $36 / 36$ & $(100)$ & $40 / 44$ & (91) & $4 / 44$ & (9) & $3-22$ \\
\hline Ice climbing & $13 \quad(6)$ & $33(30-41)$ & $13 / 13$ & $(100)$ & $6 / 13$ & $(46)$ & $7 / 12$ & (58) & $5 / 12$ & $(42)$ & $15-72$ \\
\hline Mountaineering & $11 \quad(5)$ & $27(26-35)$ & $8 / 11$ & (73) & $7 / 11$ & (64) & $8 / 10$ & $(80)$ & $2 / 10$ & (20) & $3-56$ \\
\hline $\begin{array}{l}\text { Snowshoeing or } \\
\text { hiking }\end{array}$ & $8 \quad(4)$ & $22(18-29)$ & $7 / 8$ & (88) & $3 / 4$ & (75) & $8 / 8$ & $(100)$ & $0 / 8$ & (0) & $0-37$ \\
\hline
\end{tabular}

Note: $\mathrm{Cl}=$ confidence interval, $\mathrm{IQR}=$ interquartile range, $\mathrm{NA}=$ not applicable.

*Age was missing for 1 backcountry skier.

tDoes not include the 2 deaths attributed to hypothermia.

\#For calculating percentages for cause of death, the denominator is the sum of number who died of asphyxia and number who died from trauma for each type of activity.

§For binomial proportion of trauma.

ПBackcountry skiing is skiing and snowboarding that is entirely self-propelled and that takes place in the backcountry, away from lift-serviced ski areas.

**Helicat skiing involves the use of helicopters and snowcats to access backcountry terrain away from lift-serviced ski areas, for both skiing and snowboarding.

t+Out-of-bounds skiing involves the use of ski lifts to access uncontrolled terrain beyond the boundaries of ski areas, for both skiing and snowboarding.

$\neq \ddagger$ Control work is professional avalanche control. 
single-system trauma. In these cases, the median Abbreviated Injury Scale score for the head region was 3 (interquartile range $3-4)$, which is ranked as serious. Neck injury accounted for $8 \%(2 / 24)$ of the cases with single-system trauma. In these cases, the median Abbreviated Injury Scale score for the neck region was 5 , which is ranked as critical. Abdominal injury occurred in 4\% (1/24) of the cases of single-system trauma, and the Abbreviated Injury Scale score was 3.

In $32(68 \%)$ of the 47 trauma deaths in which the object hit was recorded, the victims hit trees (Appendix 2, available at www.cmaj.ca/cgi/content/full/180/5/507/DC2).

Among the trauma deaths, 23 (48\%) of the 48 victims were completely buried, whereas $142(92 \%)$ of the 154 asphyxia deaths involved complete burial $(p<0.001)$. In these cases, the median duration of burial was 25 minutes (interquartile range $10-56$ minutes) for trauma victims and 45 minutes (interquartile range 20-231 minutes) for asphyxia victims $(p=0.009)$. The depth of burial also differed significantly for trauma and asphyxia victims (median $90 \mathrm{~cm}$ [interquartile range $30-120 \mathrm{~cm}$ ] v. $150 \mathrm{~cm}$ [interquartile range $100-200 \mathrm{~cm}] ; p<0.001)$.

The proportion of victims who wore a combination electronic transmitter-receiver (avalanche transceiver) ranged from $8 \%$ (95\% CI 0\%-36\%) among the 13 ice climbers and $13 \%$ (95\% CI 2\%-40\%) among the 15 out-of-bounds skiers for whom transceiver use was recorded to $100 \%$ (95\% CI $92 \%-100 \%$ ) for the 42 helicat skiers for whom transceiver use was recorded (Appendix 3, available at www.cmaj.ca /cgi/content/full/180/5/507/DC2). Data were insufficient to assess the use of helmets or other safety devices.

Table 3: Severity of trauma for the 117 autopsies performed

Immediate cause of death; no. $(\%)$ of cases*

\begin{tabular}{|lrcrr}
\cline { 2 - 5 } $\begin{array}{l}\text { Classification } \\
\text { of severity }\end{array}$ & $\begin{array}{c}\text { Asphyxia } \\
n=92\end{array}$ & $\begin{array}{c}\text { Trauma } \\
n=25\end{array}$ \\
\hline $\begin{array}{l}\text { Injury severity } \\
\text { scoret }\end{array}$ & & & & \\
\hline $0-11$ & 79 & $(86)$ & 0 & $(0)$ \\
\hline $12-15$ & 1 & $(1)$ & 1 & $(4)$ \\
\hline $16-24$ & 5 & $(5)$ & 6 & $(24)$ \\
\hline $25-40$ & 4 & $(4)$ & 7 & $(28)$ \\
\hline $41-49$ & 2 & $(2)$ & 0 & $(0)$ \\
\hline $50-74$ & 1 & $(1)$ & 4 & $(16)$ \\
\hline 75 & 0 & $(0)$ & 7 & $(28)$ \\
\hline Median (IQR) & 1 & $(0-9)$ & 30 & $(22-75)$ \\
\hline Major external & & & & \\
traumaf & & & 18 & $(72)$ \\
\hline Present & 4 & $(4)$ & 7 & $(28)$ \\
\hline Not present & 88 & $(96)$ & & \\
\hline
\end{tabular}

Note: IQR = interquartile range.

*Unless stated otherwise.

tClassified according to levels in the Multiple Trauma Outcome Study. ${ }^{16}$

¥As documented on initial external examination before internal dissection.
Cardiopulmonary resuscitation was performed on scene in 96 (51\%; 95\% CI 44\%-59\%) of 187 cases for which such data were available. Prehospital advanced life-support was provided in 40 (21\%; 95\% CI 15\%-27\%) of 192 cases. Cardiopulmonary resuscitation was not performed in $6(55 \%)$ of the 11 cases in which single-system chest trauma was the cause of death.

Blood ethanol levels exceeded the legal limit of $80 \mathrm{mg} / \mathrm{dL}$ $(17.4 \mathrm{mmol} / \mathrm{L})$ in $3 \%(5 / 160)$ of cases in which alcohol testing was performed (Appendix 4, available at www.cmaj.ca /cgi/content/full/180/5/507/DC2). Cannabinoids were detected in $13 \%(7 / 55)$ of cases in which drug testing was performed (Appendix 5, available at www.cmaj.ca/cgi/content/ full/180/5/507/DC2).

\section{Interpretation}

We found that asphyxia was the dominant cause of avalanche-related deaths and that trauma was relatively common as the immediate cause of death. Overall, trauma was the single immediate cause of death in $24 \%$ of cases. The proportion of deaths attributable to trauma in our study varied significantly with activity, ranging from $9 \%$ for snowmobilers to $42 \%$ for ice climbers.

Trauma was also a significant contributing factor in a substantial proportion of asphyxia deaths. We found that $13 \%$ (12/92) of asphyxia victims who underwent autopsy had major trauma, defined as an injury severity score greater than $15 .{ }^{16}$ If the entire population of 204 fatalities is considered, this results in 10\% (20/204) of cases with combined trauma and asphyxia, over and above the $24 \%$ (48/204) of cases determined to be caused by trauma alone. Thus, in western Canada, during the study period, major trauma contributed to a total of $33 \%$ (68/204) of avalanche deaths overall and, for ice climbers, to more than $50 \%(7 / 13)$ of deaths. In our study, trees were identified as the most common objects hit in trauma deaths. This may be explained by the much greater access to forested ski terrain in $\mathrm{Canada}^{20}$ than in Europe. In a recent study from Utah, United States, trauma was the immediate cause of death in $5.4 \%$ of cases and contributed to death in an additional $8.9 \%$ of 56 avalanche fatalities. ${ }^{21}$ Variations between studies point to differences in geography, such as mountain topography and distances for rescue flights, as well as demographics, notably different activity types. ${ }^{9,21-23}$

Experts stress the importance of avalanche survival strategies such as trying to escape, discarding potential anchors such as skis and creating a breathing space around the chest and face. ${ }^{24,25}$ However, any trauma suffered while caught in an avalanche may impair survival strategies and increase the risk of burial and asphyxia. ${ }^{26}$ Focusing on a single "immediate cause of death," as is typical in forensic reports and mortality databases, may obscure the combined effects of trauma, asphyxia and hypothermia in avalanche fatalities. This may be further clouded by the nonspecific and inconclusive postmortem findings in asphyxia ${ }^{27}$ and hypothermia. ${ }^{28}$ An avalanche victim who suffers any degree of trauma, even minor musculoskeletal trauma, may cease to struggle and may thus come to rest entrapped in the debris and die from a combina- 
tion of trauma, asphyxia and hypothermia, rather than from 1 of these causes alone.

Young skiers and snowboarders were over-represented in our series. The Canadian Avalanche Centre should continue to focus on education of this high-risk group, ${ }^{29}$ and social science research is essential to determine effective education strategies. $^{30}$

Various safety devices have been developed to reduce morbidity and mortality in an avalanche. Avalanche experts consider 1 such device, the transceiver, as essential. ${ }^{24}$ Only $8 \%$ of ice climbers and $13 \%$ of out-of-bounds skiers in our study were wearing transceivers.

Head trauma accounted for 10 (42\%) of 24 cases of singlesystem trauma death in our study, which supports the recommendation that helmets be worn in avalanche terrain. ${ }^{20,26}$ Our finding of a far greater risk of trauma than reported elsewhere, coupled with a low proportion of cases involving complete burial, should prompt critical analysis of the risk spectrum of each activity group in western Canada's mountain terrain. The results of such an analysis should be used to guide adoption of other devices such as inflatable airbags $\mathrm{s}^{8,22,31,32}$ and breathing implements. ${ }^{21,23,33}$

In our study, $51 \%$ of victims received cardiopulmonary resuscitation, and $21 \%$ received prehospital advanced life support. We were unable to assess whether these interventions were indicated. Also, our study did not capture information on cases in which resuscitation was successful. In 2001, a valuable resuscitation algorithm was developed. ${ }^{34}$ In the light of our findings of a significant incidence of trauma, we recommend that this algorithm be revised to take traumatic injury into account.

\section{Limitations}

Our study had limitations attributable to its retrospective design. We did not examine potential changes over the 21 years of our study that might have reflected trends in safety measures or in rescue and resuscitation techniques. There may have been differences in how the individual forensic investigators reported injuries, even though they received similar training and followed standard reporting formats. ${ }^{27}$ Another limitation is the nonspecific and inconclusive postmortem findings typical of asphyxia ${ }^{27}$ and hypothermia. ${ }^{28}$

Mortality studies such as ours benefit from the mandatory reporting and investigation of fatalities. However, we could not assess the overall health consequences of avalanche incidents, because we did not analyze survivor data. These data are currently subject to reporting losses, as survivors often fail to report their involvement in avalanches. ${ }^{5}$ Therefore, future research should involve prospective designs that capture important morbidity and mortality data for every avalancherelated injury or death.

\section{Conclusion}

Asphyxia and severe trauma cause most avalanche fatalities in western Canada. The relative rates differ between snowmobilers and those engaged in other mountain activities. Furthermore, these fatality patterns differ from European studies, which have reported trauma death rates of about $5 \%$. The dif- ferences are likely due to variations in terrain preferences and mountain topography. Our findings should guide recommendations for safety devices, safety measures and resuscitation.

This article has been peer reviewed.

Competing interests: None declared.

Contributors: The study was conceived and designed by Jeff Boyd, Pascal Haegeli, Riyad Abu-Laban and Michael Shuster. John Butt contributed his expertise as a forensic pathologist in the conceptual design of the study and the analysis and interpretation of autopsy and external examination data. Jeff Boyd and Pascal Haegeli were responsible for data extraction and Pascal Haegeli and Riyad Abu-Laban for statistical analysis. Jeff Boyd initially drafted the article, and all of the authors made critical revisions and gave final approval of the manuscript. Jeff Boyd was responsible for overall supervision of the study.

Acknowledgements: We thank Terry Smith, Chief Coroner, and Tej Sidhu of the British Columbia Coroners Service, and Graeme Dowling, Chief Medical Examiner, and Kim Borden and Barbara Hinman of the Office of the Chief Medical Examiner, Alberta Justice, for providing access to mortality data; Rosemary Armour, Ministry of Health Services of BC, for providing additional data; Christi Findlay, Regional Trauma Services, Calgary, for abstraction training and reliability testing; and Clair Israelson and John Kelly, Canadian Avalanche Centre, for providing access to avalanche data and for data confirmation. We also thank the following individuals for data confirmation: Paul Langevin; Marc Ledwidge, Steve Blake and Lisa Paulson, Parks Canada; George Field, Kananaskis Country, Alberta; Walter Bruns, Jon R. Bezzola and Rob Rohn, Canadian Mountain Holidays Inc. for administrative support; and Bruce Jamieson and Chris Stethem.

Funding: No external funding was received for this research.

\section{REFERENCES}

1. Campbell C, Bakermans L, Jamieson B, et al. Current and future snow avalanche threats and mitigation measures in Canada. Revelstoke (BC): Canadian Avalanche Centre; 2007. Available: www.avalancheinfo.net/Newsletters and Articles /Articles/AvalancheThreatsMitigationCanada.pdf (accessed 2009 Feb. 7).

2. Jamieson B, Geldsetzer T. Trends and patterns in avalanche accidents. In: Avalanche accidents in Canada: Volume 4: 1984-1996. Revelstoke (BC): Canadian Avalanche Association; 1996. p. 5-20.

3. Tough SC, Butt JC. A review of 19 fatal injuries associated with backcountry skiing. Am J Forensic Med Pathol 1993;14:17-21.

4. Page CE, Atkins D, Shockley LW, et al. Avalanche deaths in the United States: a 45-year analysis. Wilderness Environ Med 1999;10:146-51.

5. Harvey S, Signorell C, Genswein M. Avalanche accidents in back country terrain of the Swiss alps: new investigations of a 30 year database. In: International Snow Science Workshop 2002 Committee, editors. Proceedings of the International Snow Science Workshop; 2002 Sep 29-Oct 4; Penticton (BC). Available: www.avalanche.org / issw2004/issw_previous/2002/flashsite/Rescue_and_Survival/Harvey\%20poster1 \%20revision.html (accessed 2009 Feb. 7).

6. International Commission for Alpine Rescue, Avalanche Rescue, Terrestrial Rescue and Medical Commissions. Avalanche safety devices and systems. Marthalen, Switzerland: The Commission; 2006. Available: www.ikar-cisa.org/ikar-cisa/documents 12007/20061014-Statement-Avalanche-Safety-Dev-E.pdf (accessed 2009 Feb. 7).

7. Brugger H, Durrer B; International Commission for Mountain Emergency Medicine. On-site treatment of avalanche victims ICAR-MEDCOM-recommendation. High Alt Med Biol 2002;3:421-5.

8. Brugger H, Etter HJ, Zweifel B, et al. The impact of avalanche rescue devices on survival. Resuscitation 2007;75:476-83.

9. Hohlrieder M, Brugger H, Schubert HM, et al. Pattern and severity of injury in avalanche victims. High Alt Med Biol 2007;8:56-61.

10. Schaerer PA. Fatal accidents and property damage, 1978-1984. Vol 3 of Avalanche accidents in Canada. 3rd ed. Ottawa (ON): National Research Council of Canada; 1987.

11. Stethem C, Jamieson B, Schaerer P, et al. Snow avalanche hazard in Canada - a review. Nat Hazards 2003;28:487-515.

12. Accident statistics 1950-2007. Boulder (CO): Colorado Avalanche Information Center; 2006. Available: http://avalanche.state.co.us/pub/images/Accidents /Slide11.JPG (accessed 2009 Feb. 7).

13. Haegeli P. Winter backcountry use trend estimates for western Canada. Revelstoke (BC): Canadian Avalanche Association; 2005. Available: http://avalancheinfo.net /ADFAR\%20Proj\%20Docs/CAABackcountryUseTrends.pdf (accessed 2009 Feb. 7).

14. Canadian Avalanche Association. Appendix B: Reporting avalanche incidents. In: Observation guidelines and recording standards for weather, snowpack and avalanches. 5th ed. Revelstoke (BC): Canadian Avalanche Association; 2007. p. 59-67. 
15. Baker SP, O'Neill B, Haddon WJ, et al. The injury severity score: a method for describing patients with multiple injuries and evaluating emergency care. $J$ Trauma 1974; 14:187-96.

16. Champion HR, Copes WS, Sacco WJ, et al. The Major Trauma Outcome Study: establishing national norms for trauma care. J Trauma 1990;30:1356-65.

17. Gennarelli TA, Wodzin E, editors. Abbreviated injury scale 2005. 7th rev. Barrington (IL): Association for the Advancement of Automotive Medicine; 2007.

18. Cohen J. Weighted kappa - nominal scale agreement with provision for degrees of disagreement. Am Psychol 1967;22:544.

19. Zar JH. Biostatistical analysis. 5th ed. Upper Saddle River (NJ): Prentice Hall; 2004

20. Williams R, Delaney T, Nelson E, et al. Speeds associated with skiing and snowboarding. Wilderness Environ Med 2007;18:102-5.

21. McIntosh SE, Grissom CK, Olivares CR, et al. Cause of death in avalanche fatalities. Wilderness Environ Med 2007;18:293-7.

22. Radwin MI, Grissom CK. Technological advances in avalanche survival. Wilderness Environ Med 2002;13:143-52.

23. Radwin MI. Unburying the facts about avalanche victim pathophysiology. Wilder ness Environ Med 2008;19:1-3.

24. McClung D, Schaerer PA. Safety measures and rescue. In: The avalanche handbook. Seattle (WA): Mountaineers Books; 2006. p. 238-65.

25. Brugger H, Flora G, Falk M. [Self-rescue-techniques and post-traumatic stress disorders in avalanche accidents.] Notarzt 2002;18:1-4. German.

26. Johnson SM, Johnson AC, Barton RG. Avalanche trauma and closed head injury: adding insult to injury. Wilderness Environ Med 2001;12:244-7.

27. Knight B, Saukko PJ. Knight's forensic pathology. 3rd ed. New York (NY): Arnold; 2004.

28. Nixdorf-Miller A, Hunsaker DM, Hunsaker JC 3rd. Hypothermia and hyperthermia medicolegal investigation of morbidity and mortality from exposure to envi- ronmental temperature extremes. Arch Pathol Lab Med 2006;130:1297-304.

29. Canadian Avalanche Centre. Youth programs. Revelstoke (BC): Canadian Avalanche Centre; 2008. Available: www.avalanche.ca/CAC_Youth_Programs (accessed 2009 Feb. 7).

30. McCammon I, Haegeli P. Out-of-bounds avalanche awareness: assessment, current practices and future management. In: Campbell C, Conger S, editors. Proceedings of the International Snow Science Workshop; 2008 Sep 21-27; Whistler (BC). Revelstoke (BC): Canadian Avalanche Association; 2008.

31. Kern M, Tschirky F, Schweizer J. Field tests of some new avalanche rescue devices. In: International Snow Science Workshop 2002 Committee, editors. Proceedings of the International Snow Science Workshop; 2002 Sep 9-Oct 4; Penticton (BC). Available: http://akxtreme.net/Downloads/Misc/SFISAR2000.pdf (accessed 2009 Feb. 7)

32. Tschirky F, Schweizer J. Avalanche balloons - preliminary test results. In: International Snow Science Workshop 1996 Committee, editors. Proceedings of the International Snow Science Workshop; 1996 Oct 6-11; Banff (AB). Available: www.avalanche.org/ issw/96/art70.html (accessed 2009 Feb. 7).

33. Grissom CK, Radwin MI, Harmston $\mathrm{CH}$, et al. Respiration during snow burial using an artificial air pocket. JAMA 2000;283:2266-71.

34. Brugger H, Durrer B, Adler-Kastner L, et al. Field management of avalanche victims. Resuscitation 2001;51:7-15.

Correspondence to: Dr. Jeff Boyd, Emergency Department, Mineral Springs Hospital, 305 Lynx St., Box 1050, Banff AB T1L 1H7; fax 403 762-4193; jbaviifs@telus.net

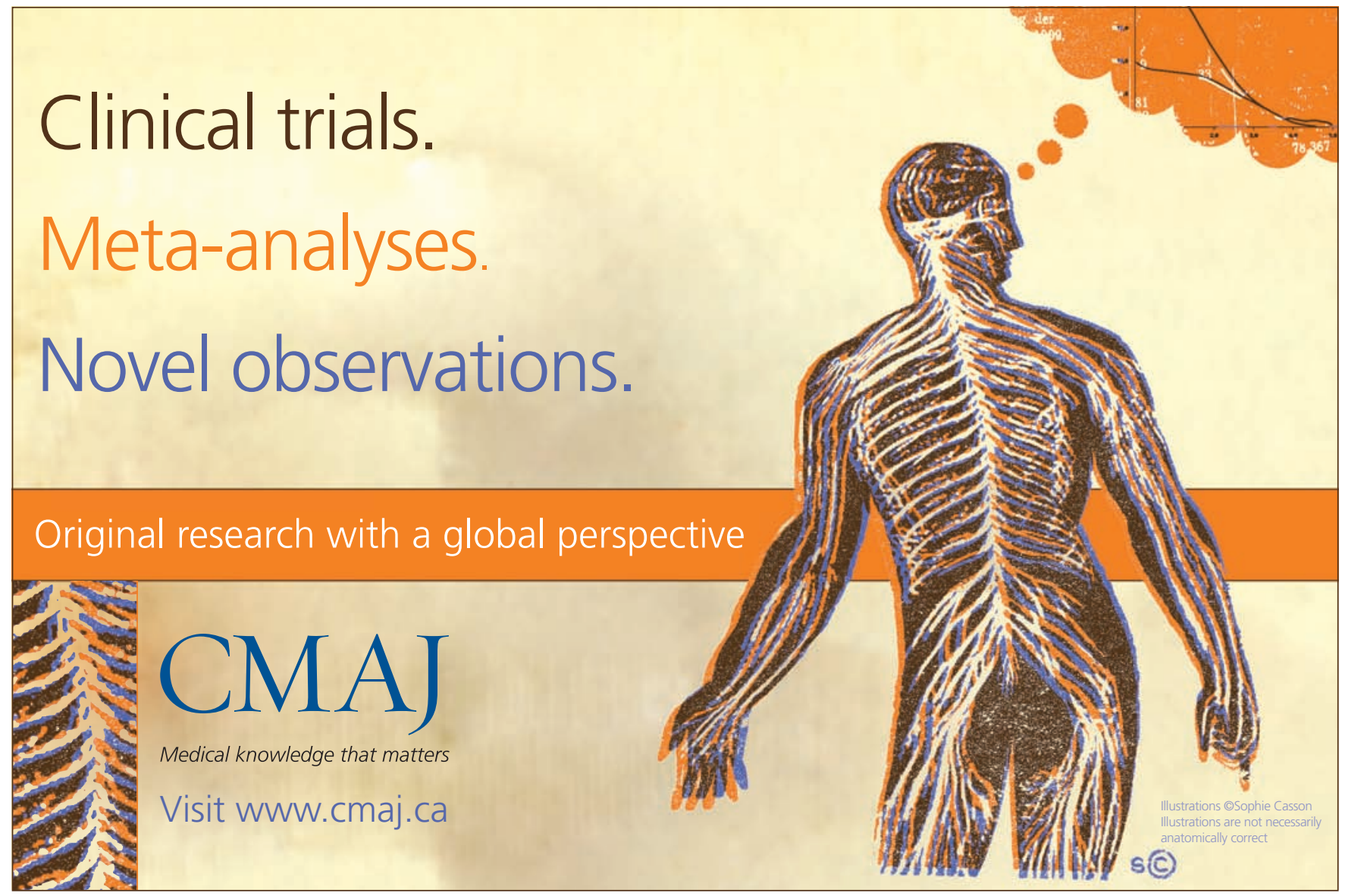

